\title{
Long-term survival with multiple metastasectomies for pulmonary osteosarcoma: a case report
}

\author{
Satoshi Takamori", Hiroyuki Oizumi, Jun Suzuki and Katsuyuki Suzuki
}

\begin{abstract}
Background: Repeat pulmonary metastasectomy (PM) considerably improves the prognosis of patients with pulmonary metastases of osteosarcoma. Reports have demonstrated a significantly improved prognosis in patients who have undergone repeat metastasectomy for osteosarcoma; however, there have been no reports with more than six metastasectomies. Herein, we describe the long-term survival of a patient following resection of multiple tumors and other treatments for metastatic osteosarcoma.
\end{abstract}

Case presentation: A 28-year-old woman underwent extensive resection and postoperative adjuvant chemotherapy for right tibial sarcoma. Over the years, she developed repeated pulmonary metastases. First, 116 metastases were removed from the bilateral lungs. After that, multiple PMs of approximately 250 tumors and other treatments for deep metastatic lesions were performed. The patient died of the underlying disease 24 years after the primary surgery.

Conclusions: This case report demonstrates the long-term survival benefit of a multidisciplinary treatment centered on multiple metastasectomies.

Keywords: Pulmonary metastasectomy, Osteosarcoma, Multiple surgery, Pregnancy

\section{Background}

Pulmonary metastasectomy (PM) has become the standard therapy for various pulmonary metastatic malignancies. It has also been performed for pulmonary metastases of osteosarcoma [1-3]. Reports have demonstrated a significantly improved prognosis in patients who have undergone PMs for osteosarcoma; however, there have been no reports of more than six metastasectomies $[2,3]$. This case report describes the long-term survival of a patient who underwent PMs of approximately 250 tumors for metastatic osteosarcoma.

\section{Case presentation}

The patient was a 28 -year-old woman who underwent extensive resection and postoperative adjuvant chemotherapy for right tibial sarcoma. Four years later, multiple bilateral pulmonary metastases were observed (Fig. 1a). The patient refused chemotherapy because she was planning to get pregnant; therefore, she was referred to our division, where she underwent bilateral PMs. We first removed 116 metastases from the bilateral lungs (Table 1). Metastatic tumors were enucleated using neodymium:yttrium-aluminum-garnet (Nd-YAG) laser. Moreover, 3 years after the initial metastasectomy, the patient became pregnant. Multiple pulmonary metastases were observed again $10,13,15,17$, and 23 years after the initial surgery. On each occasion, we consulted the attending orthopedic surgeons, who recommended metastasectomy. The patient was informed of the risks of reoperation, but she refused chemotherapy each time; with her consent, metastasectomy was performed at each
*Correspondence: s-takamori@med.id.yamagata-u.ac.jp

Department of Surgery II, Faculty of Medicine, Yamagata University, 2-2-2 lida-Nishi, Yamagata 990-9585, Japan (c) The Author(s) 2021. Open Access This article is licensed under a Creative Commons Attribution 4.0 International License, which permits use, sharing, adaptation, distribution and reproduction in any medium or format, as long as you give appropriate credit to the original author(s) and the source, provide a link to the Creative Commons licence, and indicate if changes were made. The images or other third party material in this article are included in the article's Creative Commons licence, unless indicated otherwise in a credit line to the material. If material is not included in the article's Creative Commons licence and your intended use is not permitted by statutory regulation or exceeds the permitted use, you will need to obtain permission directly from the copyright holder. To view a copy of this licence, visit http://creativecommons.org/licenses/by/4.0/. 


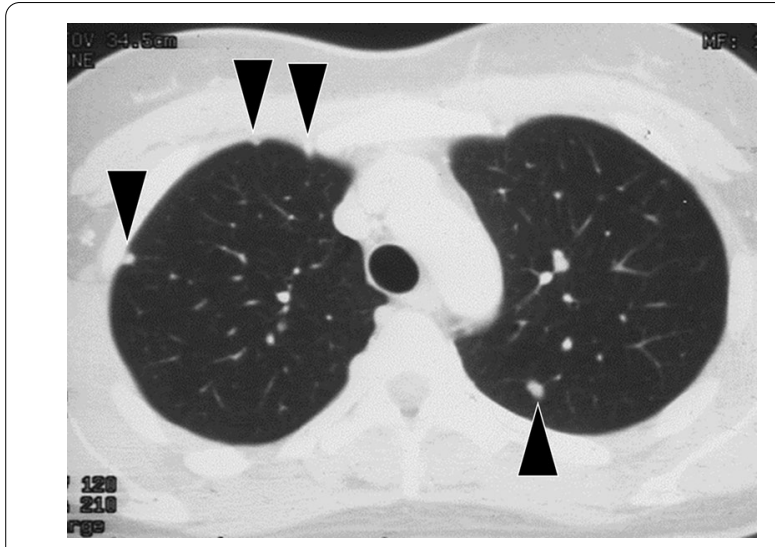

Fig. 1 Preoperative image of the first relapse. Computed tomography revealing multiple pulmonary lesions (arrows) (a)

time point. At 17 years after the initial surgery, a large lung metastasis was observed again (Fig. 2a). Because multiple PMs were performed, extensive and very severe adhesions were found in her chest cavity. As segmentectomy could not be performed, partial resection (precision cautery excision method) was performed. We performed thoracotomy just above the tumor by French window thoracotomy; a Y-shaped incision was made in the pleura. In the precision cautery excision method, after palpating and marking the target tumor, the lung parenchyma was excised in a round shape while securing safe surgical margins. Conventional electrocauterization and vessel sealing system were used to outline the area corresponding to the size of the tumor, and then the lung parenchyma was gradually divided. After the removal of the lung parenchyma, the central side was ligated, and the tumor was removed. The defect was closed using sutures [4] (Fig. 2b, Additional file 1: Video 1). The defect after lung parenchyma resection gradually recovered (Fig. 2c, d). For deep metastases, various treatments were performed. Radiofrequency ablation (RFA) for a deep pulmonary lesion and radiation therapy for a tumor near the aortic arch and pulmonary artery were performed (Fig. 3a, b). The tumors shrank or stopped growing after both treatments. At 50 years of age, the patient underwent her sixth metastasectomy. In total, approximately, 250 tumors were surgically resected during her treatment course (Table 1). A new pulmonary lesion was detected after 1 year, accompanied by a metastatic lesion in the right ventricle (Fig. 4a, b). The patient refused chemotherapy and requested palliative treatment. While on palliative treatment, she died of the underlying disease 24 years after the primary surgery. This case report was approved by the Ethics Committee of the Faculty of Medicine, Yamagata University (\#2020-S-41), and informed consent was obtained to publish this report.

\section{Discussion}

A survey of 146 members of the European Society of Thoracic Surgeons found that $53 \%$ of respondents could not place a limit on the number of repeat metastasectomies they would perform [5]. In our case, we opted for repeat PMs because it has been associated with improved survival [2,3]. Prior studies on PM for osteosarcoma have reported a 5-year overall survival rate of 19-35\%, emphasizing the importance of achieving an R0 resection [2, 3]. Moreover, $40 \%$ of patients who relapse after pulmonary resection exhibit recurrence in the lung [6]; thus, repeat PM may be a viable treatment option $[2,3]$.

For patients undergoing repeat PMs, selection for preoperative chemotherapy itself is a negative predictor, irrespective of the response, as only patients with moreaggressive underlying disease processes are selected for multimodal treatment [2]. It has also been suggested that disease progression while undergoing chemotherapy is an independent prognostic factor for poor survival [7]. Our patient was a young woman who wanted to have

Table 1 A summary of the patient's findings during follow-up and the various treatments undertaken

\begin{tabular}{|c|c|c|c|c|c|c|}
\hline $\begin{array}{l}\text { Time } \\
\text { from the primary } \\
\text { surgery (years) }\end{array}$ & Approach & Treatment & Device & No. of tumors & Right & Left \\
\hline$x+4$ & PLT & Bilateral partial resection ${ }^{\mathrm{a}}$ & Nd-YAG laser & 116 & 55 & 61 \\
\hline$x+10$ & PLT & Bilateral partial resection ${ }^{\mathrm{a}}$ & Nd-YAG laser & 69 & 18 & 51 \\
\hline$x+13$ & PLT & Right S6b subsegmentectomy and partial resection ${ }^{a}$ & Electrocautery & 55 & 55 & \\
\hline$x+15$ & FWT & Left partial resection & Electrocautery & 3 & & 3 \\
\hline$x+17$ & FWT & $\begin{array}{l}\text { Right partial resection }{ }^{a} \\
\text { Radiofrequency ablation (deep lesion) }\end{array}$ & Vessel sealing system & 1 & 1 & \\
\hline$x+19$ & & Radiation therapy (hilar lesion) 60 Gy/8 Fr & & & & \\
\hline$x+23$ & $\mathrm{PLT}$ & Right $\$ 9+10$ segmentectomy and partial resection ${ }^{a}$ & Ultrasonic coagulating sears & 5 & 5 & \\
\hline
\end{tabular}

PLT posterolateral thoracotomy, FWT French window thoracotomy, Nd-YAG laser neodymium:yttrium-aluminum-garnet laser

a Pulmonary partial resection was performed without stapling 


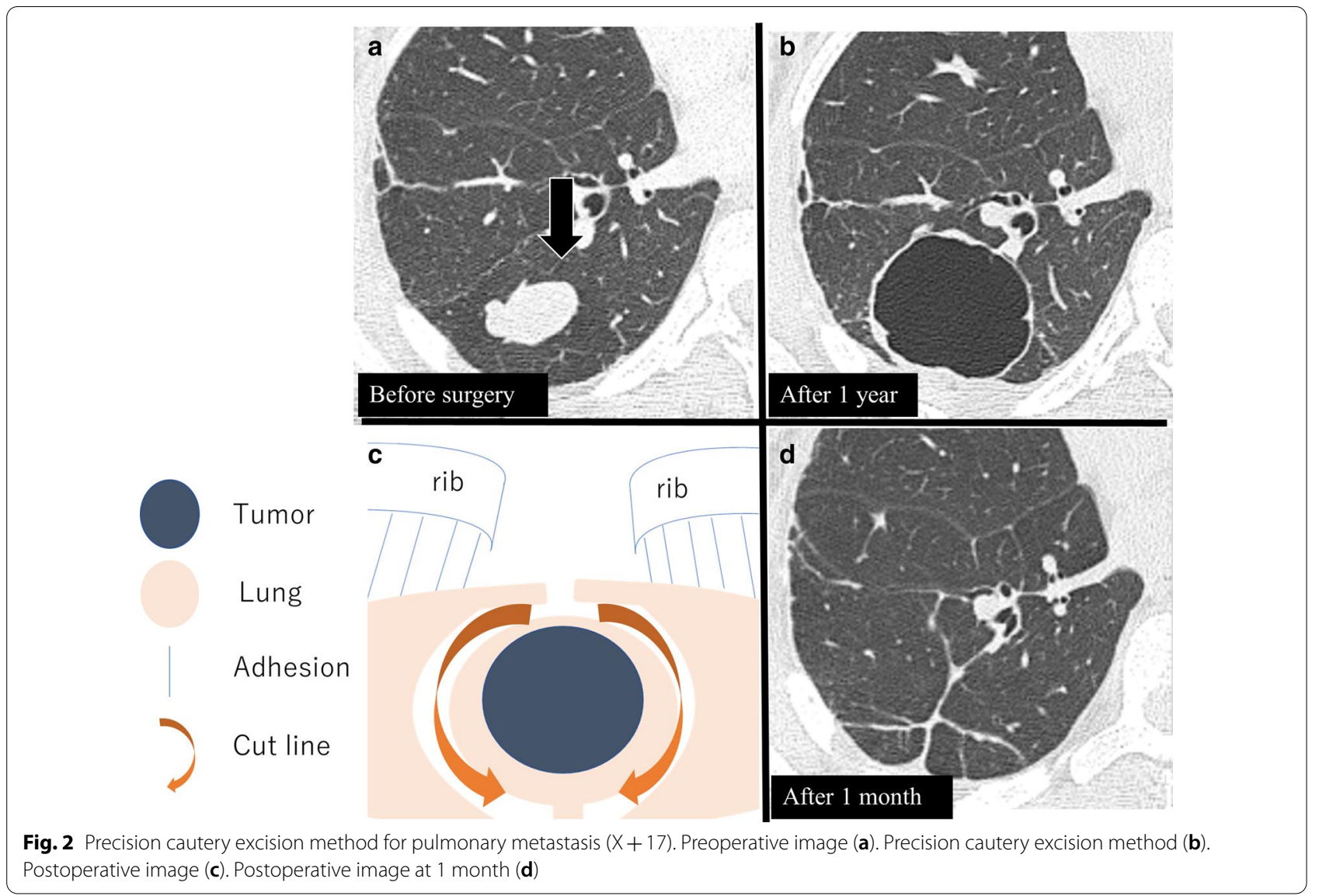

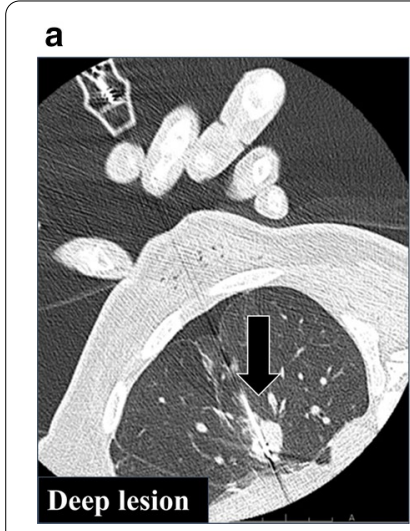

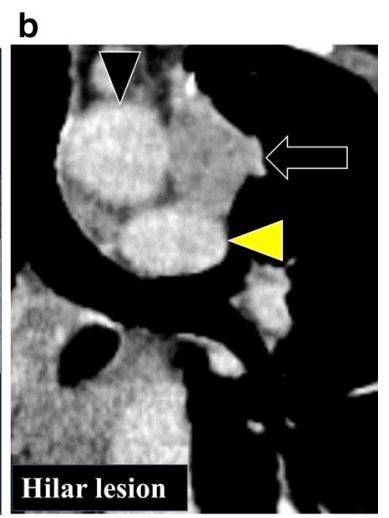

Fig. 3 Pretreatment approach for metastatic lesions. Computed tomography revealing a deep pulmonary lesion (arrows), which is treated using radiofrequency ablation (a). Radiation therapy is performed for a lesion near the aortic arch (black arrowhead) and pulmonary artery (yellow arrowhead) (b)

children. Therefore, chemotherapy was not feasible, and PMs were repeated.

RFA, carbon ion radiotherapy, and radiation therapy have been reported to be effective for unresectable lung lesions and cases in which lung preservation is expected [8-11]. RFA and radiotherapy can be expected to control the tumor $[8,9,11]$. In this case, respiratory function was preserved by performing segmentectomy or partial resection (the precision cautery excision method) [4], while deep metastatic lesions were controlled by RFA and radiation therapy. Pulmonary resection, such as the precision cautery excision method, can minimize pulmonary resection and the decrease in lung function [4]. Even with large tumor size and intrathoracic adhesions, the French window thoracotomy allowed us to perform the operation with minimal impact of adhesions [12]. Repeat metastasectomies were performed using Nd-YAG laser or segmentectomy to preserve the lung function $[13,14]$. Hence, the patient could tolerate multiple operations.

In our case, the patient developed right ventricular metastasis. Reports of right ventricular metastasis of osteosarcoma are known, which may be due to hematogenous metastasis of the tumor $[15,16]$. 


\section{a}

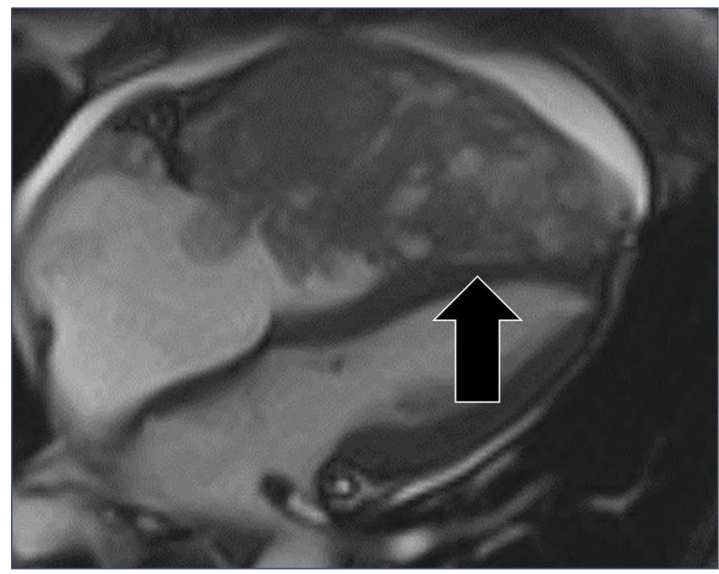

b

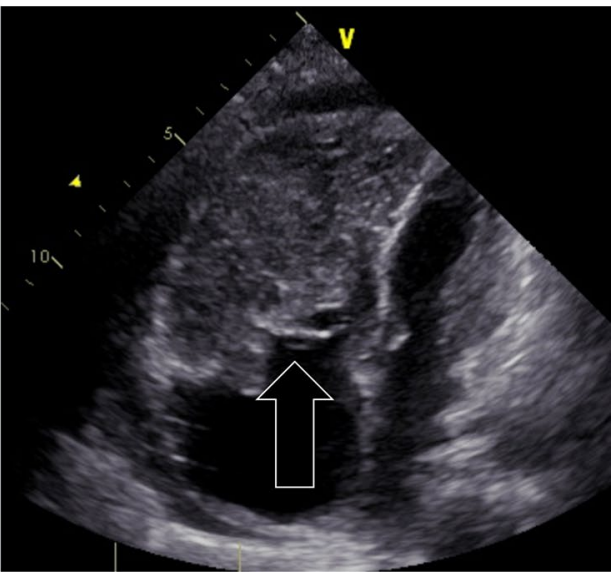

Fig. 4 Image at last follow-up. Magnetic resonance imaging (a) and echocardiography (b) confirm a massive metastasis in the right ventricle (arrow)

\section{Conclusion}

This case report demonstrates the long-term survival benefit of a multidisciplinary treatment centered on multiple metastasectomies. Multiple metastasectomies are risky but can be an option.

\section{Supplementary Information}

The online version contains supplementary material available at https://doi. org/10.1186/s40792-020-01106-2.

Additional file 1: Video 1. Precision cautry excision method $(X+17)$.

\section{Abbreviations}

PM: Pulmonary metastasectomy; PLT: Posterolateral thoracotomy; FWT: French window thoracotomy; Nd-YAG laser: Neodymium:yttrium-aluminum-garnet laser; RFA: Radiofrequency ablation.

\section{Acknowledgements}

We would like to thank Editage (www.editage.com) for English language editing.

\section{Authors' contributions}

ST acquired the data and drafted the manuscript. $\mathrm{HO}$ and JS, and KS reviewed and edited the manuscript. All authors read and approved the final manuscript.

\section{Funding}

None.

\section{Availability of data and materials}

Not applicable.

\section{Ethics approval and consent to participate}

The case report was approved by the Ethics Committee of the Faculty of Medicine, Yamagata University (\#2020-S-41), and an informed consent was obtained.

\section{Consent for publication}

Informed consent was obtained for the publication of this report and accompanying images.

\section{Competing interests}

The authors declare that they have no competing interests.

Received: 29 October 2020 Accepted: 28 December 2020

Published online: 13 January 2021

\section{References}

1. Briccoli A, Rocca M, Salone M, Bacci G, Ferrari S, Balladelli A, et al. Resection of recurrent pulmonary metastases in patients with osteosarcoma. Cancer. 2005;104:1721-5.

2. Chudgar NP, Brennan MF, Tan KS, Munhoz RR, D'Angelo SP, Bains MS, et al. Is repeat pulmonary metastasectomy indicated for soft tissue sarcoma? Ann Thorac Surg. 2017;104:1837-45.

3. Chen F, Miyahara R, Bando T, Okubo K, Watanabe K, Nakayama T, et al. Repeat resection of pulmonary metastasis is beneficial for patients with osteosarcoma of the extremities. Interact Cardiovasc Thorac Surg. 2009:9:649-53.

4. Cooper JD, Perelman M, Todd TR, Ginsberg RJ, Patterson GA, Pearson FG. Precision cautery excision of pulmonary lesions. Ann Thorac Surg. 1986;41:51-3.

5. Internullo E, Cassivi SD, Van Raemdonck D, Friedel G, Treasure T, ESTS Pulmonary Metastasectomy Working Group. Pulmonary metastasectomy: a survey of current practice amongst members of the European Society of Thoracic Surgeons. J Thorac Oncol. 2008;3:1257-66.

6. Martini N, Huvos AG, Mike V. Multiple pulmonary resections in the treatment of osteogenic carcinoma. Ann Thorac Surg. 1971;12:271-80.

7. Stephens EH, Blackmon SH, Correa AM, Roth JA, Rice DC, Hofstetter W, et al. Progression after chemotherapy is a novel predictor of poor outcomes after pulmonary metastasectomy in sarcoma patients. J Am Coll Surg. 2011;212:821-6.

8. Ding JH, Chua TC, Glenn D, Morris DL. Feasibility of ablation as an alternative to surgical metastasectomy in patients with unresectable sarcoma pulmonary metastases. Interact Cardiovasc Thorac Surg. 2009;9:1051-3.

9. Saumet L, Deschamps F, Marec-Berard P, Gaspar N, Corradini N, Petit $P$, et al. Radiofrequency ablation of metastases from osteosarcoma in patients under 25 years: the SCFE experience. Pediatr Hematol Oncol. 2015:32:41-9.

10. Matsumoto K, Imai R, Kamada T, Maruyama K, Tsuji H, Tsujii H, et al. Working Group for bone and soft tissue sarcomas soft tissue, impact of carbon ion radiotherapy for primary spinal sarcoma. Cancer. 2013;119:3496-503. 
11. Loi M, Duijm M, Baker S, Rossi L, Grunhagen D, Verhoef C, et al. Stereotactic body radiotherapy for oligometastatic soft tissue sarcoma. Radiol Med. 2018;123:871-8.

12. Yamaguchi A, Hashimoto O, Tamaki S. French-window thoracotomy: postoperative pain avoidance for short-stay lung cancer surgery. Jpn J Thorac Cardiovasc Surg. 2007;54:520-7.

13. Kodama K, Doi $\mathrm{O}$, Higashiyama M, et al. Surgical management of lung metastases: usefulness of resection with the neodymium:yttrium-aluminum-garnet laser with median sternotomy. J Thorac Cardiovasc Surg. 1991;101:901-8.

14. Fanta J, Rehak F, Horak L, Kabát J, Adámek S, Marek J. Open lung surgery with Nd-YAG laser. Lasers Med Sci. 1988:4:13-6.
15. Maleki M, Mozaffari K, Givtaj N, Tatina A, Bahadorian B. Metastatic osteosarcoma and heart: a rare involvement in an unusual cardiac location. Heart Asia. 2013:5:120-1.

16. Elasfar A, Khalifa A, AIGhamdi A, Khalid R, Ibrahim M, Kashour T. Asymptomatic metastatic osteosarcoma to the right ventricle: case report and review of the literature. Saudi Heart Assoc. 2013;25:39-42.

\section{Publisher's Note}

Springer Nature remains neutral with regard to jurisdictional claims in published maps and institutional affiliations.

\section{Submit your manuscript to a SpringerOpen ${ }^{\circ}$ journal and benefit from:}

- Convenient online submission

- Rigorous peer review

- Open access: articles freely available online

- High visibility within the field

- Retaining the copyright to your article

Submit your next manuscript at $\boldsymbol{\nabla}$ springeropen.com 